\title{
OPTIMASI PERTUMBUHAN ISOLAT FUNGI INDIGEN Penicillium sp. LBKURCC153 PENDEGRADASI NAFTALENA MENGGUNAKAN GLUKOSA SEBAGAI KOSUBSTRAT PADA MINIMAL MEDIUM
}

\section{THE GROWTH OPTIMIZATION OF INDIGENOUS FUNGI ISOLATE Penicillium sp. LBKURCC153 FOR NAPHTHALENE DEGRADATION USING GLUCOSE AS COSUBSTRATE ON MINIMUM MEDIUM}

\author{
Aisyah fitrida ${ }^{1}$, Riryn Novianty ${ }^{2 *}$ Saryono $^{3}$, Amir Awaluddin ${ }^{4}$, Nova Wahyu Pratiwi ${ }^{4}$ \\ ${ }^{1234}$ Program Studi Kimia Fakultas MIPA Universitas Riau, Indonesia \\ *Email: rirynnovianty@lecturer.unri.ac.id
}

Diterima: 21 Februari 2020. Disetujui: 10 Maret 2020. Dipublikasikan: 30 April 2020

\begin{abstract}
Abstrak: Naftalena merupakan salah satu polutan yang sulit untuk didegradasi karena termasuk kedalam kelompok PAH dan bersifat karsinogenik. Tujuan dari penelitian ini adalah untuk menguji efektifitas isolat fungi indigen dari Provinsi Riau untuk mendegradasi senyawa toksik naftalena dengan penambahan glukosa sebagai kosubstrat pertumbuhan. Degradasi naftalena oleh isolat fungi dipengaruhi oleh beberapa parameter, diantaranya biomassa, $\mathrm{pH}$ dan persentase degradasi yang diukur pada 0, 4, 8, 12 dan 16 hari inkubasi. Berdasarkan dari parameter biomassa isolat fungi Penicillium sp. LBKURCC153 mengalami fase eksponensial sampai hari ke-16. Pada fase eksponensial terjadi pertambahan jumlah sel secara maksimum yang menunjukkan respon positif terhadap penggunaan glukosa dan naftalena sebagai sumber karbon dan energi. Isolat mengalami penurunan $\mathrm{pH}$ dari 7 sampai 3,8 yang artinya ada aktivitas pertumbuhan yang menghasilkan asam-asam organik dari proses degradasi naftalena. Isolat juga mampu mendegradasi naftalena sebesar $27,5 \%$ oleh Penicillium sp. LBKURCC153 pada media dengan penambahan glukosa pada waktu optimum selama 4 hari inkubasi. Kesimpulannya, penambahan kosubstrat glukosa dapat meningkatkan persentase degradasi naftalena oleh Penicillium sp. LBKURCC153.
\end{abstract}

Kata Kunci : Biodegradasi, fungi, glukosa, naftalena

Abstract: Naphthalene is one of the pollutants that is difficult to degrade because it belongs to the PAH group and it was carcinogenic. The purpose of this study was to test the effectiveness of an indigenous fungi isolate from Riau Province to degrade naphthalene toxic compounds with glucose as growth cosubstrate. Naphthalene degradation by fungi isolates was influenced by several parameters, including biomass, $\mathrm{pH}$ and percentage degradation measured at $0,4,8,12$ and 16 days of incubation. Based on biomass parameters, the isolate of Penicillium sp. LBKURCC153 experienced an exponential phase until the 16th day. In the exponential phase, the maximum number of cells increases which shows a positive response to the use of glucose and naphthalene as the carbon and energy source. Isolate decreased their $\mathrm{pH}$ from 7 to 3,8 , that mean proves the growth activity produce organic acid metabolites of degrade naphthalene. Isolate were also able to degrade naphthalene respectively $27,5 \%$ by Penicillium sp. LBKURCC153 in medium with glucose at optimation time until 4 th day incubation. In conclusion, glucose cosubstrate can increase naphthalene degradation percentage by Penicillium sp. LBKURCC153.

Keywords : biodegradation, fungi, glucose, napthalene

\section{PENDAHULUAN}

Minyak bumi adalah campuran kompleks senyawa organik yang terdiri atas senyawa hidrokarbon dan non hidrokarbon yang berasal dari sisa-sisa mikroorganisme, tumbuhan dan binatang yang tertimbun selama berjuta-juta tahun. Hidrokarbon minyak bumi merupakan senyawa organik yang terdiri dari karbon dan hidrogen dan dapat digolongkan menjadi dua jenis, yaitu hidrokarbon alifatik dan hidrokarbon aromatik [1]. Polycylic Aromatic Hydrocarbon (PAH) merupakan hidrokarbon yang mempunyai cincin benzen yang saling berikatan. Kelarutan PAH dalam air akan terus berkurang seiring dengan bertambahnya cincin benzen penyusun struktur molekul tersebut. Rendahnya kelarutan senyawa PAH menyebabkan keterbatasan biaovabilitas dan efisiensinya pada proses bioremediasi [2].

Hasil penelitian [3], PAH yang ada di tanah akan dijerap oleh partikel koloid tanah dalam waktu yang singkat. Penjerapan ini semakin lama akan semakin persisten karena terjadi akumulasi tanpa adanya penguraian oleh mikroorganisme. Hal ini disebabkan karena PAH bersifat hidrofobik yaitu memiliki tingkat kelarutan yang sangat rendah terhadap air. Sifat hidrofobik ini menyebabkan PAH berpotensi untuk mengikat bahan organik dan mampu membentuk mikropolutan yang kemudian 
terendap dalam tanah. Senyawa PAH bila masuk ke dalam darah akan diserap oleh jaringan lemak dan mengalami oksidasi dalam hati membentuk fenol. Berikutnya akan terjadi reaksi konjugasi membentuk glukoronida yang larut dalam air, kemudian masuk ke ginjal. Senyawa antara yang terbentuk adalah epoksida yang beracun dan dapat menyebabkan kerusakan pada sumsum tulang [4].

Naftalena adalah salah satu kelompok senyawa PAH dominan yang terkandung dalam minyak bumi [5]. Keracunan naftalena dapat menyebabkan penyakit anemia haemolitik dan nefrotoksisitas pada manusia [6]. Paparan naftalena pada manusia dapat merusak sel darah merah sehingga menyebabkan anemia haemolitik [7]. Untuk itu dibutuhkan suatu metode yang ramah lingkungan untuk menguraikan bahan kimia ini.

Biodegradasi oleh mikroorganisme, adalah cara yang tepat, efektif dan hampir tidak ada pengaruh sampingan pada lingkungan karena tidak menghasilkan racun [8]. Menurut [9] menyatakan bahwa mikroba indigen lebih banyak digunakan dalam proses pengolahan lahan tercemar karena lingkungannya lebih sesuai dengan lingkungan tercemar tersebut serta kemungkinannya lebih kecil untuk mengalami proses inhibisi. Penggunaan mahluk hidup berupa mikroorganisme mampu memberikan metode degradasi yang ramah lingkungan seperti fungi Aspergillus aculeatus, Aspergillus flavus dan Aspergillus fumigatus yang digunakan untuk mendegradasi limbah berbahaya [10].

Isolat fungi indigen Penicillium sp. (LBKURCC153) yang diisolasi dari tanah tercemar tumpahan minyak bumi di Badan Operasi Bersama PT Bumi Siak Pusako-Pertamina Hulu, Kabupaten Siak, Provinsi Riau telah teruji dapat mendegradasi naftalena dengan persentase degradasi naftalena oleh isolat pada media tanpa glukosa adalah sebesar 21,5\% setelah diinkubasi selama 16 hari [11]. Namun, kemampuan isolat fungi indigen tersebut dalam mendegradasi senyawa naftalena masih rendah. Efektivitas biodegradasi dapat ditingkatkan dengan memanipulasi parameter lingkungan untuk mendukung pertumbuhan mikroba dan mendegradasi dengan lebih cepat [12].

Penambahan glukosa sebagai kosubstrat mampu meningkatkan pertumbuhan mikroorganisme secara signifikan. Oleh karena itu, pada penelitian ini ditambahkan glukosa pada media MM sebagai kosubstrat pertumbuhan untuk meningkatkan keefektifan biodegradasi naftalena [9].

\section{METODE PENELITIAN}

\section{Alat dan Bahan}

Alat yang digunakan dalam penelitian ini adalah timbangan analitik (Mettler $A E$ 200), oven (Fisher Scientific Isotemp Oven model 655F), Autoclave (All America model 1925/KY-23D), waterbath (Sibata WK-24), Vortex mixer Genie $2^{\mathrm{TM}}$, orbital shaker (Daihan Labtech CO., LTD)),
Laminar Air Flow Cabinet (LAFC) (Esco Micro PTE LTD 30 Loyang Drive Singapore 1750), spektrofotometer UV-Vis (Genesys 10S UV-Vis v4.002 2L9N175013), pH meter (Horiba Scientific Laqua Act D-71G), centrifuge (Hitachi Centrifuge CT 15RE), desikator, inkubator (Heraeus Instrument D6450), corong pisah, mikropipet dan alat-alat standar laboratorium lainnya sesuai prosedur kerja.

Bahan yang digunakan pada penelitian ini adalah aluminium foil, alkohol antiseptik $70 \%$, asam sitrat, kentang, agar batang, dextrosa monohidrat, akua demineralisasi (akua DM), $\left(\mathrm{NH}_{4}\right)_{2} \mathrm{SO}_{4}$, $\mathrm{K}_{2} \mathrm{HPO}_{4}, \quad \mathrm{MgSO}_{4} .7 \mathrm{H}_{2} \mathrm{O}, \quad \mathrm{FeSO}_{4} .7 \mathrm{H}_{2} \mathrm{O}, \mathrm{KH}_{2} \mathrm{PO}_{4}$, Tween 80, naftalena, aseton, $\mathrm{NaCl}, \mathrm{NaOH}$, heksana, kapas, benang jagung, plastik wrap, kertas saring Whatman No. 42 dan spritus.

Peremajaan Isolat Fungi pada Media Potato Dextrose Agar (PDA)

Peremajaan isolat fungi dapat dilakukan dengan prosedur sebagai berikut: kentang dikupas, dicuci dan dipotong kecil-kecil lalu ditimbang sebanyak 20 gram. Kentang tersebut ditambahkan 50 $\mathrm{mL}$ akua DM dan direbus hingga mendidih, kemudian disaring dan diambil filtratnya. Selanjutnya sebanyak 1,7 gram agar batang dan 2 gram dextrose dimasukkan ke dalam filtrat dan ditambahkan akua DM hingga volume $100 \mathrm{~mL}$. Filtrat dipanaskan hingga agar batang larut. Setelah larut, media PDA disterilisasi menggunakan autoklaf pada tekanan 15 psi dan suhu $121^{\circ} \mathrm{C}$ kemudian didinginkan dan diinkubasi selama 1 jam di dalam waterbath $\left(60^{\circ} \mathrm{C}\right)$ dan ditambahkan asam sitrat $10 \%$ sebanyak $500 \mu \mathrm{L}$. Media PDA dituang ke tabung reaksi. PDA yang telah membeku didiamkan pada suhu kamar. Bila tidak ada kontaminasi, media PDA dapat digunakan.

Isolat fungi Penicillium sp. (LBKURCC153) diremajakan pada media Potato Dextrose Agar (PDA) dibuat dengan prosedur sebagai berikut: miselia fungi diambil dari biakan murni menggunakan jarum ose yang telah disterilisasi dengan api dari lampu spritus kemudian diinokulasi ke atas media agar miring PDA. Media yang sudah ditanami tersebut, kemudian diinkubasi pada suhu kamar.

\section{Starter Inokulum Fungi}

Starter Inokulum fungi dapat dilakukan dengan prosedur sebagai berikut: Miselia fungi Penicillium sp. (LBKURCC153) ditambahkan air salin $(\mathrm{NaCl}$ $0,85 \%$ ) sebanyak $3 \mathrm{~mL}$ dan diserut dengan jarum ose. Setelah itu dipipet dengan pipet mikro sebanyak 0,5 $\mathrm{mL}$ dan di masukkan ke dalam media PDA dalam petri. Kemudian di ratakan dengan batang L. Media yang sudah ditanami tersebut, kemudian diinkubasi pada suhu kamar. 


\section{Biodegradasi Naftalena Pembuatan Larutan Stok Naftalena}

Larutan stok naftalena $10 \mathrm{mM}$ dibuat dengan melarutkan $0,128 \mathrm{~g}$ naftalena dalam $50 \mathrm{~mL}$ aseton, kemudian dimasukkan kedalam labu takar $100 \mathrm{~mL}$ dan ditambahkan aseton sampai tanda batas dan dihomogenkan.

\section{Pembuatan Minimal Medium (MM) dengan Penambahan Glukosa}

Minimal Medium (MM) digunakan untuk uji degradasi naftalena oleh isolat fungi. $\mathrm{MM}$ dibuat dengan melarutkan $2 \mathrm{~g}\left(\mathrm{NH}_{4}\right)_{2} \mathrm{SO}_{4}, 1 \mathrm{~g} \mathrm{~K}_{2} \mathrm{HPO}_{4}, 1 \mathrm{~g}$ $\mathrm{KH}_{2} \mathrm{PO}_{4}, 0,2$ g $\mathrm{MgSO}_{4} .7 \mathrm{H}_{2} \mathrm{O}, 0,01$ g $\mathrm{FeSO}_{4} .7 \mathrm{H}_{2} \mathrm{O}$, $0,02 \%$ tween 80 ke dalam $1000 \mathrm{~mL}$ akua $\mathrm{DM}$ dan ditambahkan glukosa sebanyak $10 \mathrm{~g}$ (Bourguignon et al., 2014). $\mathrm{pH}$ media diukur sampai menjadi 7 . Setelah itu, media MM yang sudah ditambahkan glukosa dimasukkan kedalam Erlenmeyer $100 \mathrm{~mL}$ sebanyak 29,4 mL. Media disterilkan dalam autoklaf dengan suhu $121^{\circ} \mathrm{C}$ tekanan 15 psi selama 20 menit. Setelah media dingin, larutan naftalena $10 \mathrm{mM}$ ditambahkan ke dalam masing-masing Erlenmeyer yang berisi media sebanyak $0,6 \mathrm{~mL}$ sehingga konsentrasi akhir naftalena menjadi 0,2 mM. Kemudian media didiamkan selama 1 hari. Bila tidak ada kontaminasi, maka media dapat digunakan..

\section{Optimasi Pertumbuhan Isolat Fungi dengan Penambahan Glukosa}

Optimasi pertumbuhan isolat fungi dalam mendegradasi naftalena dengan penambahan glukosa sebagai kosubstrat pertumbuhan, dengan prosedur sebagai berikut: isolat fungi sebanyak 3 plug (diameter $5 \mathrm{~mm}$ ) diinokulasikan pada media MM $(29,4 \mathrm{~mL})$ yang sudah ditambahkan glukosa $(0,3 \mathrm{~g})$ dan naftalena $(6 \mathrm{~mL})$ dalam Erlenmeyer $100 \mathrm{~mL}$. Semua Erlenmeyer ditutup dengan kapas, kain kasa dan alumunium foil. Sebagai kontrol digunakan media MM (29,4 mL) yang sudah ditambahkan glukosa $(0,3 \mathrm{~g})$ dan naftalena $(6 \mathrm{~mL})$ tanpa isolat fungi. Eksperimen ini dilakukan secara triplo.

\section{Uji Biodegradasi Naftalena di MM cair}

Uji biodegradasi naftalena diinkubasi selama 16 hari pada rotary shaker dengan kecepatan 150 rpm pada suhu ruang. Inokulum dimonitor pada hari ke $0,4,8,12$ dan 16 dengan mengukur $\mathrm{pH}$ menggunakan $\mathrm{pH}$ meter, menghitung biomassa dengan cara mengukur berat keringnya. Sampel di saring menggunakan kertas saring Whatman no. 42. Setelah itu dikeringkan dalam oven. Selanjutnya ditimbang berat keringnya. Filtrat diambil dan ditambahkan heksana $(1: 1)$ untuk mengekstraksi naftalena. Selanjutnya disentrifugasi dengan kecepatan 1200 rpm selama 10 menit untuk memisahkan fase organik dan fase air. Kemudian 1 $\mathrm{mL}$ larutan pada fase organik diambil dan diukur absorbansinya pada hari ke $0,4,8,12$ dan 16 inkubasi menggunakan spektrofotometer UV-Vis pada panjang gelombang $289 \mathrm{~nm}$. Konsentrasi residu naftalena dapat dihitung menggunakan kurva standar naftalena dengan larutan blanko heksana. Persentase biodegradasi nafalena dapat dihitung melalui persamaan berikut [13].

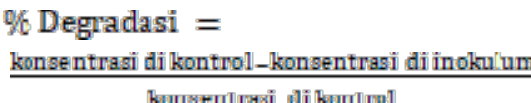

\section{Analisis Data}

Analisis data hasil analisa yang diperoleh dari penelitian ini dianalisis deskriptif dalam bentuk grafik serta dianalisis secara statistik menggunakan uji lanjutan Duncan jarak berganda taraf 5\% menggunakan program SPSS.

\section{HASIL DAN PEMBAHASAN \\ Parameter Biomassa Selama Biodegradasi Naftalena \\ Semua mikroorganisme memiliki kurva} pertumbuhan, begitupun dengan fungi. Penentuan kurva pertumbuhan fungi pada penelitian ini ditunjukkan dengan parameter biomassa. Parameter biomassa ini ditentukan berdasarkan berat kering isolat fungi dalam $\mathrm{MM}$ cair selama proses biodegradasi naftalena. Menurut [3], fungi akan menunjukkan perbedaan pola pertumbuhan berdasarkan periode waktu yang dibutuhkan untuk tumbuh maupun beradaptasi. Pertumbuhan mikroorganisme dioptimalkan dengan memanipulasi lingkungan hidupnya untuk menciptakan kondisi optimum yang mendukung pertumbuhannya [12]. Oleh karena itu, pada penelitian ini ditambahkan glukosa pada media MM yang berfungsi sebagai kosubstrat bagi masing-masing isolat.

Berdasarkan uji Duncan, pertumbuhan isolat fungi mempunyai biomassa yang berbeda secara nyata seiring dengan bertambahnya waktu inkubasi. Hasil uji Duncan dapat dilihat pada Tabel 1.

Pengukuran aktivitas ekstrak kasar enzim hasil fermentasi padat dengan variasi waktu 10, 20, dan 30 hari dilakukan untuk menunjukkan bahwa selulosa pada pulp popok bayi bekas yang mengandung urin dapat didegradasi oleh jamur selulolitik T.asperellum LBKURCC1 dan isolat bakteri S-22. Hal ini menunjukkan bahwa selulosa popok bayi bekas mengandung urin dapat digunakan sebagai sumber karbon yang bisa dilihat dari adanya aktivitas ekstrak kasar enzim selulase yang dianalisis menggunakan metode Nelson-Somogyi.

Hasil fermentasi popok bayi bekas menggunakan isolat jamur LBKURCC1 dan bakteri S-22 dapat dilihat pada Tabel 1 .

Tabel 1. Hasil uji Duncan biomassa dengan penambahan glukosa

\begin{tabular}{clllll}
\hline \multirow{2}{*}{ Isolat } & \multicolumn{5}{c}{ Waktu Inkubasi (Hari) } \\
& \multicolumn{1}{c}{0} & \multicolumn{1}{c}{4} & \multicolumn{1}{c}{8} & \multicolumn{1}{c}{12} & \multicolumn{1}{c}{16} \\
\hline Penicillium sp. & 0,407 & 1,657 & 2,093 & 2,830 & 2,967 \\
LBKURCC153 & \pm & \pm & \pm & \pm & \pm \\
& 0,032 & 0,609 & $0,272^{\mathrm{b},}$ & 0,092 & 0,873 \\
& $\mathrm{a}$ & $\mathrm{b}$ & $\mathrm{c}$ & $\mathrm{c}$ & $\mathrm{c}$ \\
\hline
\end{tabular}


Keterangan : a, b, c, d dan e merupakan rata-rata nilai biomassa dari tiga kali pengulangan. Pangkat huruf yang sama menyatakan tidak berbeda secara nyata pada tingkat $5 \%(\mathrm{p} \leq 0.05)$ pada baris yang sama berdasarkan uji Duncan.

Biomassa dari pertumbuhan isolat fungi pada media MM dengan penambahan glukosa dapat dilihat pada Gambar 1 berikut.

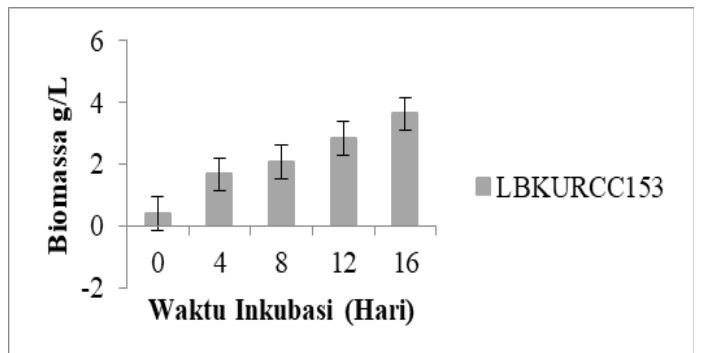

Gambar 1. Biomassa isolat fungi dalam MM cair dengan penambahan glukosa pada suhu ruang, kecepatan agitasi $150 \mathrm{rpm}$.

Isolat fungi pada Gambar 1. terlihat mampu beradaptasi dan menggunakan glukosa dan naftalena sebagai sumber karbon dalam pertumbuhannya. Hal ini dapat diketahui melalui biomassa pertumbuhan fungi yang diukur dalam rentang waktu $0,4,8,12$ dan 16 hari yang terus mengalami kenaikan. Isolat fungi LBKURCC153 mengalami fase eksponensial sampai hari ke enam belas waktu inkubasi. Menurut [14] pada fase eksponensial, mikroorganisme mengalami pertumbuhan secara cepat. Selain itu, kebutuhan energi pada fase eksponensial lebih tinggi dibandingkan pada fase lag (adaptasi), stasioner dan kematian.

Pada fase eksponensial mikroba membelah dengan cepat dan konstan. Kecepatan pertumbuhan pada fase ini sangat dipengaruhi oleh media tempat tumbuhnya seperti $\mathrm{pH}$ dan kandungan nutrien. Pada penelitian ini, pengaruh penambahan glukosa terhadap pertumbuhan fungi memberikan efek positif terhadap peningkatan biomassa dari masing-masing fungi. Terlihat bahwa dengan penambahan glukosa, fungi mempunyai biomassa sebanyak $3,63 \mathrm{~g} / \mathrm{L}$ untuk LBKURCC153 setelah diinkubasi selama 16 hari. Sedangkan menurut penelitian [11] pertumbuhan isolat fungi tertinggi pada media tanpa penambahan glukosa adalah sebesar $0,48 \mathrm{~g} / \mathrm{L}$ untuk LBKURCC153. Berdasarkan perbandingan ini dapat disimpulkan bahwa dengan penambahan glukosa dapat meningkatkan pertumbuhan isolat fungi $656 \%$.

\section{Parameter pH Selama Proses Biodegradasi}

Kemampuan mikroorganisme dalam mendegradasi hidrokarbon juga dipengaruhi oleh faktor $\mathrm{pH}$, karena $\mathrm{pH}$ menentukan aktivitas enzim yang optimal. Berdasarkan uji Duncan, pH masingmasing isolat fungi berbeda secara nyata seiring dengan bertambahnya waktu inkubasi. Hasil uji Duncan dapat dilihat pada Tabel 2. Berikut:
Tabel 2. Hasil uji Duncan $\mathrm{pH}$ pada media MM dengan penambahan glukosa

\begin{tabular}{llllll}
\hline \multirow{2}{*}{ Isolat } & \multicolumn{5}{c}{ Waktu Inkubasi (Hari) } \\
& \multicolumn{1}{c}{0} & \multicolumn{1}{c}{4} & \multicolumn{1}{c}{8} & \multicolumn{1}{c}{12} & \multicolumn{1}{c}{16} \\
\hline Penicillium sp. & 6,700 & 3,800 & 2,833 & 2,500 & 3,367 \\
LBKURCC153 & \pm & \pm & \pm & \pm & \pm \\
& 0,000 & $0,819^{\mathrm{c}}$ & $0,231^{\mathrm{a}}$, & $0,000^{\mathrm{a}}$ & $0,208^{\mathrm{b}}$ \\
& $\mathrm{d}$ & & $\mathrm{b}$ & & $\mathrm{c}$ \\
Kontrol & 6,633 & 6,533 & 6,533 & 6,533 & 6,400 \\
& \pm & \pm & \pm & \pm & \pm \\
& 0,058 & 0,058 & $0,058^{\mathrm{b}}$ & 0,058 & $0,000^{\mathrm{a}}$ \\
& $\mathrm{b}$ & $\mathrm{b}$ & & $\mathrm{b}$ & \\
\hline
\end{tabular}

Keterangan : $a, b, c$ dan d merupakan rata-rata nilai $\mathrm{pH}$ dari tiga kali pengulangan. Pangkat huruf yang sama menyatakan tidak berbeda secara nyata pada tingkat $5 \% \quad(\mathrm{p} \leq 0.05)$ pada baris yang sama berdasarkan uji Duncan.

Perubahan $\mathrm{pH}$ media MM dengan penambahan glukosa selama degradasi naftalena dapat dilihat pada Gambar 2 berikut:

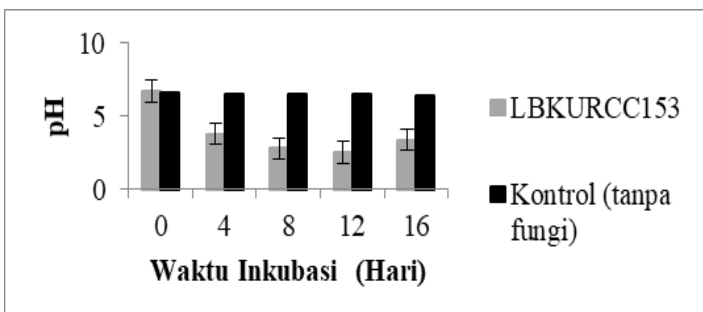

Gambar 2. Perubahan $\mathrm{pH}$ media dengan penambahan glukosa selama proses degradasi naftalena pada suhu ruang, agitasi $150 \mathrm{rpm}$

Pada Gambar 2. dapat dilihat terjadinya penurunan $\mathrm{pH}$ pada media yang ditambahkan glukosa dari pH 7 menjadi 3,8. Penurunan $\mathrm{pH}$ ini dapat terjadi karena adanya aktivitas pertumbuhan dari fungi dan juga terbentuknya asam-asam organik akibat dari degradasi naftalena oleh fungi yang mengakibatkan $\mathrm{pH}$ menjadi lebih asam. [15] menyatakan hasil degradasi naftalena oleh fungi menghasilkan forma dan naftol yang dimetabolisme menjadi salisilaldehid yang dioksidasi menjadi asam salisilat dan didehidroksilasi menjadi asam benzoat. Menurut [16], peningkatan keasaman kemungkinan besar terkait dengan produksi metabolit asam, seperti asam benzoat dan ftalat selama biodegradasi naftalena.

Hasil penelitian [11], $\mathrm{pH}$ media tanpa penambahan glukosa pada isolat fungi LBKURCC153 dari pH 7 menjadi 6,3. Hasil ini dapat dilihat bahwa media dengan penambahan glukosa mengalami penurunan $\mathrm{pH}$ yang lebih asam bila dibandingkan dengan media tanpa penambahan glukosa yang diteliti oleh [11], hal ini berarti pada media dengan glukosa fungi mempunyai pertumbuhan yang lebih banyak sehingga asamasam organik yang terbentuk juga menjadi lebih banyak sehingga naftalena semakin banyak yang terdegradasi. 


\section{Persentase Degradasi Naftalena Selama Proses Biodegrdasi}

Persentase kemampuan biodegradasi isolat fungi ditentukan berdasarkan konsentrasi naftalena menggunakan spektrofotometer UV-Vis pada panjang gelombang $289 \mathrm{~nm}$. Konsentrasi naftalena yang terdegradasi selama waktu inkubasi dapat ditentukan melalui kurva standar naftalena dengan larutan blanko heksana. Pembuatan kurva standar bertujuan untuk mengetahui serapan masing-masing konsentrasi dari larutan standar, kemudian dibuat grafik hubungan konsentrasi larutan standart dengan serapan [17]

Tabel 3. Persentase degradasi naftalena pada media dengan penambahan glukosa setelah inkubasi enam belas hari.

\begin{tabular}{lccccc}
\hline Isolat & $\begin{array}{c}\text { Waktu } \\
\text { Inkuba } \\
\mathbf{s i} \\
\text { (Hari) }\end{array}$ & $\begin{array}{c}\text { Bio } \\
\text { mas } \\
\mathbf{s a} \\
\mathbf{( g /} \\
\mathbf{L})\end{array}$ & $\mathbf{p H}$ & $\begin{array}{c}\text { Konsent } \\
\text { rasi } \\
\mathbf{( m M )}\end{array}$ & $\begin{array}{c}\text { Perse } \\
\mathbf{n} \\
\text { degra } \\
\text { dasi } \\
\mathbf{( \% )}\end{array}$ \\
\hline $\begin{array}{l}\text { LBKU } \\
\text { RCC15 }\end{array}$ & 0 & 0,41 & 6,7 & 0,2 & 0 \\
\cline { 2 - 6 } 3 & 4 & 1,67 & 3,8 & 0,09 & 27,5 \\
\cline { 2 - 6 } & 8 & 2,09 & 2,8 & 0,059 & 22 \\
\cline { 2 - 6 } & 12 & 2,83 & 2,5 & 0,051 & 11 \\
\hline & 16 & 3,63 & 3,4 & 0,025 & 27,5 \\
\hline
\end{tabular}

Perhitungan persentase degradasi perlu dilakukan untuk mengetahui dengan pasti kemampuan terbaik suatu isolat dalam mendegradasi naftalena. Persentase degradasi naftalena oleh isolat fungi dapat dilihat pada Tabel 3. Pada Tabel 3. dapat dilihat bahwa persentase degradasi naftalena tertinggi oleh Penicillium sp. LBKURCC153 setelah diinkubasi selama 4 hari adalah 27,5\%.

Berdasarkan persentase degradasi naftalena untuk masing-masing isolat fungi pada media dengan penambahan glukosa adalah sebesar $27,5 \%$ oleh isolat fungi LBKURCC153. Bila dibandingkan dengan penelitian [11] persentase degradasi naftalena tertinggi untuk isolat fungi pada media tanpa glukosa adalah $19 \%$ oleh isolat fungi LBKURCC153. Dari kedua perbandingan ini dapat disimpulkan bahwa dengan penambahan glukosa dapat meningkatkan persentase degradasi naftalena sebesar $30,9 \%$.

Glukosa dapat meningkatkan pertumbuhan fungi sehingga ketika glukosa sudah mulai habis, fungi tersebut akan menggunakan naftalena sebagai sumber karbon lain yang menyebakan persentase degradasi menjadi meningkat. Hasil ini sesuai dengan penelitian yang dilakukan oleh [18] bahwa penambahan kosubstrat glukosa pada media meningkatkan persentase degradasi benzo [a]pirena oleh isolat fungi sebesar dua kali lipat dari persentase media tanpa penambahan glukosa.

\section{KESIMPULAN}

Berdasarkan penelitian yang telah dilakukan, dapat disimpulkan bahwa dengan penambahan kosubstrat glukosa dapat meningkatkan persentase degradasi naftalena oleh Penicillium sp. LBKURCC153 dengan persentase degradasi 27,5\% diikuti biomassa fungi sebesar $1,67 \mathrm{~g} / \mathrm{L}$ dan penurunan $\mathrm{pH}$ menjadi 3,8 dengan waktu optimum selama 4 hari inkubasi.

\section{DAFTAR PUSTAKA}

[1] Agustin, S. N. R. 2015. Biodegradasi minyak bumi dengan menggunakan bakteri indigen Pseudomonas peli dari sumur tua desa Babat Toman Musi Banyuasin (MUBA). Skripsi. Palembang: Universitas Sriwijaya.

[2] Li, J. L., \& Chen, B. H. 2009. Surfactantmediated biodegradation of polycyclic aromatic hydrocarbons. J. Materials, 2.76-94.

[3] Sari, G. L. 2015. Biodegradasi polycylic aromatic hydrocarbon (PAH) pada tanah terkontaminasi batubara dengan metode cocomposting. Tesis. Surabaya: Institut Teknologi Sepuluh Nopember.

[4] Kappell, A. D., et al. 2014. The polycyclic aromatic hydrocarbon degradation potential of gulf of mexiconative coastal microbial communities after deepwater horizon oil spill. Frontiers in Microbiology, 5, .1-14.

[5] Farini, N. 2016. Optimasi kemampuan degradasi senyawa naftalena oleh bakteri laut dan deteksi gennaftalena dioksigenase. Skripsi. Bogor: Institut Pertanian Bogor.

[6] Lohmann, R., Breivik, K., Dachs, J., \& Muir, D. 2007. Global fate of POPs: current and future research directions. Environ Pollut, 150.150-165.

[7] Fardani, N. F. 2018. Biotransformasi metilen biru oleh jamur pelapuk putih Phlebia lindtneri. Skripsi. Surabaya: Institut Teknologi Sepuluh Nopember.

[8] Juliani, A., Lathifah, A. N. d\& Nurdin, W. A. 2016. Pengaruh penambahan kosubstrat pada biodegradasi crude oil. Jurnal Sains dan Teknologi Lingkungan, 8(2).112-120.

[9] Ubaidillah, N.A., Purnomo, A.S., \& Putri, E.M.M. 2014. Biodegradasi metilen biru menggunakan jamur pelapuk coklat Gleophyllum trabeum. Jurnal Seni dan Sains, 2(1).1-6.

[10] Fitrida, A., Apriyana, K., Astuti, R \& Novianty, R. 2019. Biodegradasi senyawa toksik naftalena menggunakan isolat fungi indigen provinsi Riau. Laporan Penelitian PKM Ristekdikti 2019. FMIPA UNRI, Pekanbaru.

[11] Vidali, M. 2001. Bioremediation. Puer and Applied Chemistry, 7(73).1163-1172. 
[12] Trikurniadewi, N. 2015. Biodegradasi naftalen dan fenantren oleh Bacillus subtilis 3KP. Skripsi. Surabaya: Universitas Airlangga.

[13] Kosim, M. \& S. R. Putra. 2010. Pengaruh suhu pada protease dari Bacillus subtilis. Prosiding Skripsi Semester Genap 2009-2010. Jurusan Kimia FMIPA ITS Surabaya.

[14] Elhusseiny, S. M., Amin, H. M \& Shebl, R. I. 2018. Modulation of laccase transcriptome during biodegradation of naphthalene by white rot fungus Pleurotus ostreatus. International Microbiology,

[15] Bumpus, J. A., Tien, M., Wright, D. \& Aust, S. D. 1985. Oxidation of persistent environmental pollutants by a white rot fungus. Science, 228 (4706).1434-1436.

[16] Saputra, R., Noviyanti., \& Cahyani, D. I. 2019. Pemanfaatan kulit pisang dalam degradasi zat aktif piridaben pada pestisida samite 135EC. Jurnal Iptek Terapan, 13(i1).1-11.

[17] Hadibarata, T \& Kristanti, R.A. 2012. Fate and cometabolic degradation of benzo[a]pyrene by white-rot fungus Armillaria sp. F022. Bioresource Technology, 107.314-318. 